\title{
Prototipe Pengontrol Kunci Pintu Berbasis Arduino Uno Menggunakan RFID Studi Pada Smks Kesehatan Utama Insani
}

\author{
Asep Hardiyanto Nugroho ${ }^{1}$, Al-Bahra Bin Ladjamudin ${ }^{2}$, Siti Bariroh ${ }^{3}$ \\ 1,2 Jurusan Teknik Informatika TI Universitas Islam Syekh-Yusuf \\ Jln. Maulana Yusuf No 10 - Babakan Kota Tangerang \\ 1asep.hardiyanto@unis.ac.id \\ 2albahra@unis.ac.id \\ 3barirohsiti09@gmail.com
}

\begin{abstract}
Intisari- Dalam rangka meningkatkan keamanan, SMKS kesehatan Utama Insani memperkerjakan seorang security untuk memegang kendali keamanan siswa dan lingkungannya. Security akan bekerja memantau perilaku siswa dan memantau keamanan setiap ruang yang ada. Namun sistem keamanan yang ada tidak berjalan dengan efektif, dimana hal ini disebabkan karena keterbatasan seorang security yang terkadang masih melakukan kesalahan dan kelalaian dalam memantau keamanan siswa dan ruangan. Untuk membantu meringankan tugas security dibutuhkan sistem keamanan yang lebih canggih dan efektif. Dalam penelitian ini, sistem keamanan yang digunankan adalah keamanan pintu berbasis Arduino Uno menggunakan RFID (Radio Frequency Identification), dimana RFID sering juga dikenal dengan istilah sensor tag ID yang cukup terkenal dan sering digunakan dalam bidang elektronika mikrokontroler. RFID merupakan sensor yang mengidentifikasi suatu objek dengan menggunakan frekuensi radio.
\end{abstract}

Kata Kunci : keamanan, Arduino Uno, RFID, mikrokontroler

Abstract - In order to improve security, SMKS Primary Health Insani hired a security to hold control of students ' security and environment. Security will work to monitor student behaviour and monitor the security of any existing space. But the existing security system does not run effectively, where this is due to the limitation of a security that sometimes still make mistakes and omissions in monitoring the security of students and rooms. To help relieve security tasks needed a more sophisticated and effective security system. In this research, the security system that is used is the security of Arduino-based door Uno using RFID (Radio Frequency Identification), where RFID is often also known as a tag sensor that ID is quite famous and often used in field of electronic microcontroller. RFID is a sensor that identifies an object using radio frequency.

Keywords - Security, Arduino Uno, RFID, microcontroller

\section{PENDAHULUAN}

Menciptakan sekolah yang aman, nyaman, dan disiplin sangatlah penting agar siswa dapat mencapai prestasi yang terbaik dan guru dapat menampilkan kinerja yang terbaik. Sekolah yang aman, nyaman dan disiplin adalah sekolah yang warga sekolahnya bebas dari rasa takut, kondusif untuk belajar dan hubungan antar warga sekolahnya positif. Sekolah yang aman, nyaman, dan disiplin menyediakan lingkungan fisik (gedung, kelas, halaman) sekolah yang bersih dan aman.

SMKS Kesehatan Utama Insani yang terletak di Jl. AMD. 09 Panongan - Citra Raya Tangerang adalah sekolah menengah kejuruan swasta dalam bidang kesehatan. SMKS ini mempunyai dua jurusan yang diunggulkan yaitu jurusan Farmasi dan jurusan Keperawatan. SMKS Kesehatan Utama Insani sebagai instansi pendidikan yang saat ini sedang berkembang dalam dunia pendidikan dan kesehatan telah menyediakan pembekalan dalam dunia kesehatan dengan berbagai bagian materi dan praktikum yang telah memiliki ruangan masing-masing sesuai dengan kebutuhannya.

Menggunakan Arduino Uno akan memungkinkan suatu sistem kontrol hak akses ruangan, sehingga pekerjaan pengontrolan dalam penggunaan ruangan lebih mudah dijalani dan waktu kerja lebih efisien, namun pekerjaan tetap terkontrol dengan baik. Salah 
satu pengembangan Arduino Uno untuk menunjang keamanan ruangan adalah perancangan alat pengontrol kunci pintu ruangan yang lebih canggih dan aman.

Dari observasi peneliti dalam proses pengontrolan pintu di SMKS Kesehatan Utama Insani kurang efisien dan kurang aman. Sehingga mengakibatkan beberapa masalah yang timbul seperti penggunaan ruangan tidak pada waktunya, dimana ketika jam pelajaran telah selesai, masih ada beberapa siswa/i yang tetap berada di ruangan. Serta kerusakan pada beberapa inventaris, karena kurangnya pengawasan terhadap ruangan, sering kali terjadi kerusakan inventaris laboratorium yang disengaja ataupun tidak disengaja.

\section{A. Rumusan Masalah}

Berdasarkan identifikasi yang telah diuraikan di atas rumusan masalah yang diteliti sebagai berikut:

1. Bagaimana cara membuat alat keamanan ruangan yang canggih dan aman?

2. Bagaimana cara membuat pengontrol hak akses pintu menggunakan mikrokontroler?

3. Bagaimana cara membantu security dalam melaksanakan tugasnya untuk mengontrol setiap pintu yang ada di SMKS Kesehatan Utama Insani?

\section{B. Batasan Masalah}

Berdasarkan latar belakang yang telah diuraikan diatas. Penulis membatasi permasalahan serta ruang lingkupmya, agar penelitian ini dapat dilaksanakan lebih fokus, sempurna dan mendalam, maka penulis hanya membahas tentang:

1. Pengontrol kunci pintu ruangan menggunakan Arduino Uno

2. Input yang digunakan untuk mengakses pintu adalah Sensor Tag/RFID

3. Batasan ruang lingkup hanya pada SMKS Kesehatan Utama Insani - Panongan - Citra Raya - Tangerang

\section{Tujuan Penelitian}

Adapun beberapa tujuan dalam perancangan pengontrol kunci pintu ini adalah:

1. Membuat suatu alat keamanan menggunakan mikrokontroler Arduino Uno, sehingga pintu dapat terkunci secara otomatis.

2. Menggunakan Sensor Tag/RFID sebagai pengontrol kunci pintu ruangan, sehingga memungkinkan pintu terbuka otomatis hanya untuk pengguna yang telah memiliki hak akses.

3. Membuat alat pengontrol hak akses kunci pintu dalam penggunaan ruangan, sehingga diharapkan security tidak perlu bergerak berpindah tempat untuk mengontrol siapa yang menggunakan setiap ruangan yang ada di SMKS Kesehatan Utama Insani.

\section{Manfaat Penelitian}

Adapun beberapa manfaat dalam perencangan pengontrol kunci pintu ini adalah:

1. Bagi Penulis hasil penelitian ini diharapkan mampu memberikan pengetahuan yang bermanfaat dalam bidang elektronika mikrokontroler serta dapat dikembangkan lagi sebagai media pembelajaran materi lebih dalam lagi.

2. Bagi Instansi yang bersangkutan diharapkan dapat meringankan pekerjaan security dalam mengontrol pintu ruangan serta meminimalisir waktu kerja agar lebih efisien namun tetap terkontrol dengan baik, selain itu juga diharapkan mampu memberikan keamanan bagi penggunaan hak akses ruangan di SMKS Kesehatan Utama Insani.

3. Bagi Universitas hasil penelitian ini diharapkan dapat menjadi suatu referensi atau masukan bagi perkembangan teknik serta menjadi kajian teknik khususnya bidang Teknik Informatika di Universitas Islam Syekh Yusuf Tangerang. Terutama untuk mengetahui bagaimana sistem kerja pengontrol kunci pintu ruangan berbasis web menggunakan Arduino Uno. 


\section{LANDASAN TEORI}

\section{A. Teknologi Informasi}

Istilah teknologi sering tercampur aduk dengan istilah sistem informasi dan sering kali menjadi bahan diskusi hingga perdebatan. Ada yang menggunakan istilah teknologi informasi untuk menggambarkankan sekumpulan sistem informasi. Pendapat ini menjabarkan teknologi dalam pandangan yang luas. Namun, jika didasarkan pada definisi sistem informasi menurut Arter adalah bahwa teknologi informasi hanyalah bagian dari sistem informasi [1].

\section{B. Definisi Mikrokontroler}

Mikrokontroler adalah suatu mikroprosesor yang dikhususkan dalam instrumentasi dan kendali. Mikrokontroler adalah suatu alat elektronik digital yang memiliki masukan (input) dan keluaran (output) serta kendali dengan program yang dapat ditulis serta dihapus dengan cara yang khusus, cara kerja mikrokontroler sebenarnya membaca dan menulis data. [2]

Definisi lain menyebutkan bahwa dalam beberapa diskusi dapat disimpulkan bahwa mikrokontroler merupakan komputer yang memiliki ukuran mikro dalam satu chip IC (integrated circuit) yang terdiri dari processor, memory, dan antarmuka yang dapat diprogram. Disebut komputer mikro karena dalam IC atau chip mikrokontroler terdiri dari CPU, memory serta $\mathrm{I} / \mathrm{O}$ yang bisa kita kontrol dengan memprogramnya. I/O juga sering disebut dengan GPIO (General Purpose Input Output Pins) yang berarti: pin yang dapat diprogram sebagai input atau output sesuai kebutuhan.

\section{Arduino}

Jenis-jenis Arduino berdasarkan perkembangan teknologi khusususnya dalam bidang elektronika telekomunikasi serta industri, terdapat sebuah sistem mikrokontroler terbaru yang disebut Arduino dengan platform open source yang sangat komprehensif yang dirancang untuk mobile devices.
Sama halnya seperti Mikrokontroler yang memiliki banyak jenisnya, Arduino muncul dan berkembang dengan berbagai jenis produk, jenisjenis yang paling umum dikalangan para praktisi antara lain [5]

\section{Arduino Uno}

Arduino Uno merupakan suatu rangkaian platform elektronika yang bersifat open source yang dikembangkan dari mikrokontroller berbasis ATmega328.

Beberapa kelebihan yang dimiliki oleh Arduino Uno adalah:

1. Murah - board Arduino Uno relatif murah dibandingkan dengan platform mikrokontroler lain.

2. Cross-Platform - Arduino Software IDE dapat dijalankan pada sistem operasi Windows, Macintosh OSX, dan juga Linux. Kebanyakan sistem mikrokontroler yang lain terbatas untuk dijalankan pada sistem operasi Windows.

3. Simple - perangkat lunak Arduino IDE sangat mudah digunakan untuk pemula, namun cukup flexibel untuk pengguna tingkat lanjut.

4. Perangkat lunak Arduino diterbitkan sebagai tools open source. Bahasanya dapat diperluas melalui library $\mathrm{C}++$.

5. Arduino Board diterbitkan dibawah lisensi creative commons, sehingga perancang sirkuit yang berpengalaman dapat membuat modul versi mereka sendiri, memperluaskannya dan meningkatkannya.

Modul Arduino Uno yang telah dijelaskan diatas dapat ditunjukan pada gambar berikut:

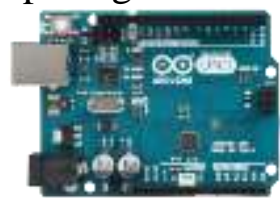

gambar 1 Modul Arduino Uno

Sumber : Mudah Belajar Mikrokontroler Arduino 


\section{E. Relay}

Relay adalah saklar elektrik yang menggunakan electromagnet untuk memindahkan saklar dari posisi OFF ke posisi ON. Daya yang dibutuhkan untuk mengaktifkan relay relatif kecil. Namun, relay dapat mengendalikan sesuatu yang membutuhkan daya lebih besar.

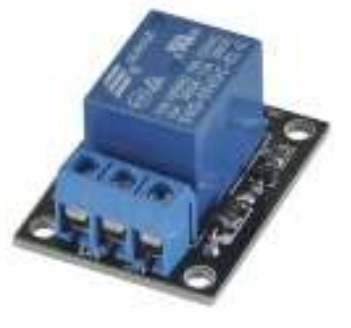

$$
\text { gambar } 2 \text { Modul Relay }
$$

Sumber: www.jaycar.com.au/

Terdapat beberapa jenis konfigurasi relay, missal Single Pole Single Throw (SPST) dan Single Pole Double Throw (SPDT) yang ditunjukan gambar dibawah ini:

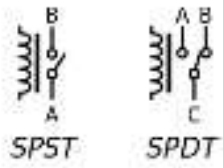

gambar 3 Konfigurasi Relay SPST dan Relay SPDT

Sumber: www.datasheetcafe.com/

Untuk mengendalikan output berdasarkan konsisi yang diberikan pada Relay dengan alur, Arduino akan mengendalikan Relay dengan memberikan logika High dan Low pada Relay dan selanjutnya output logika yang diberikan kepada Relay akan menentukan apakah elemen output bekerja sesuai perintah [3].

\section{F. Solenoid Door Lock}

Solenoid Door Lock sebagai alat yang sering digunakan untuk membuat kunci pintu otomatis. Solenoid ini akan bergerak atau bekerja apabila diberi tegangan. Tegangan Solenoid Kunci Pintu ini rata-rata yang dijual dipasaran adalah 12 volt tapi ada juga yang 6volt dan 24volt. Pada kondisi normal solenoid dalam posisi tuas memanjang atau terkunci. Jika diberi tegangan tuas akan memendek atau terbuka. Solenoid ini juga dapat digabungkan dengan sistem pengunci elektrik berbasis RFID ataupun menggunakan password.

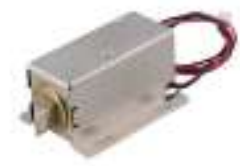

gambar 5 Solenoid Door Lock

Sumber: www.amazon.com/

\section{G. Sensor Tag/RFID}

Sensor RFID atau biasa disebut sensor tag merupakan sensor yang mengidentifikasi suatu objek dengan menggunakan frekuensi radio, sensor ini terdiri dari dua bagian yang penting, yaitu transceiver (reader) dan transponder (tag), dimana reader sendiri akan membaca data dari tag dengan perantara gelombang radio sedangkan setiap tag menyimpan data yang berbeda, data tersebut merupakan data identitas tag, mikrokontroler ini berfungsi untuk mengolah data yang didapat pada reader.

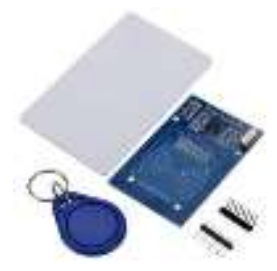

H. LCD Arduino

gambar 4 Sensor Tag RFID

Sumber: www.jakartanotebook.com/

Tampilan LCD terdiri dari dua bagian, yakni bagian panel LCD yang terdiri dari banyak "titik". LCD dan sebuah mikrokontroler yang menempel dipanel dan berfungsi mengatur ,titik-titik ${ }^{\text {ee }}$ LCD tadi menjadi huruf atau angka yang terbaca. 


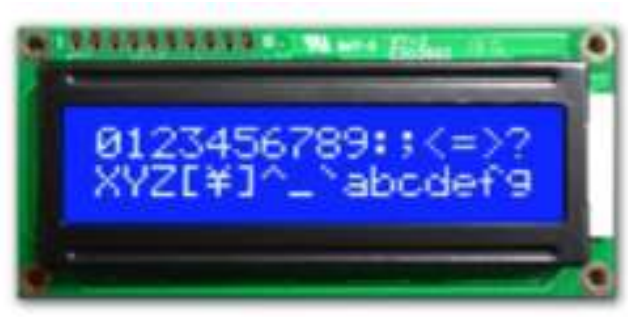

gambar 6 LCD 16x2

Huruf atau angka yang akan ditampilkan dikirim ke LCD dalam bentuk kode ASCII, kode ASCII ini diterima dan diolah oleh mikrokontroller di dalam LCD menjadi ,titik-titik ${ }^{\text {ee }}$ LCD yang terbaca sebagai huruf atau angka. Dengan demikian tugas mikrokontroller pemakai tampilan LCD hanyalah mengirimkan kode-kode ASCII untuk ditampilkan [4].

\section{METODOLOGI PENELITIAN}

Dalam sebuah penelitian tentunya ada sebuah metode yang digunakan pada penelitian ini, peneliti menggunakan metode pengumpulan data sebagai berikut:

\section{A.Data Primer}

Penelitian ini memerlukan data primer, pengumpulan data primer yang diperlukan yaitu:

\section{1) Metode Observasi}

Melalui metode observasi peneliti melakukan observasi langsung di SMKS Kesehatan Utama Insani Panongan - Citra Raya Tangerang, obeservasi dilakukan guna melihat sistem kerja keamanan pintu ruangan yang ada, lokasi serta tata letak pintu.

\section{2) Metode Interview}

Melalui metode interview peneliti melakukan wawancara langsung pada tgl 30 April 2018 dengan pihak yang bersangkutan dengan keamanan pintu serta Kepala Sekolah SMKS Kesehatan Utama Insani Panongan - Citra Raya - Tangerang.

\section{B. Data Sekunder}

Penelitian ini memerlukan data sekunder, pengumpulan data sekunder yang diperlukan yaitu Study literature adalah cara yang dipakai untuk menghimpun data-data atau sumbersumber yang berhubungan dengan topik yang diangkat dalam suatu penelitian. Studi literatur bisa didapat dari berbagai sumber, jurnal, buku dokumentasi, internet dan pustaka.

\section{Analisis Kebutuhan}

Analisis adalah kegiatan pendalaman, penelaahan, pengelompokan, penafsiran, sistematisasi serta verifikasi data yang berasal dari hasil pengumpulan data yang dilakukan sebelumnya. Guna mendapatkan hasil kebutuhan yang sesuai maka dilakukan analisis kebutuhan melalui empat tahap, yaitu:

1. Survey terhadap sistem kerja pengontrol pintu yang sedang berjalan

2. Analisis terhadap temuan survey

3. Identifikasi temuan survey

4. Identifikasi penyeselaian masalah

\section{HASIL DAN PEMBAHASAN}

\section{A. Prosedur Pengujian}

Pengujian yang dilakukan meliputi pengujian perangkat keras (hardware) dan perangkat lunak (software) yang diharapkan dari pengujian ini akan didapat suatu sistem yang mampu menjalankan rancangan alat berjalan dengan baik dan optimal. Adapun prosedurnya sebagai berikut :

1. Sambungkan Modul Arduino Uno dengan USB Cable Download Arduino

2. Selanjutnya aktifkan komputer dan jalankan program Arduino IDE

3. Sambungkan USB Cable Download Arduino yang telah tersambung dengan Modul Arduino Uno ke komputer

4. Buka sketch Arduino IDE. 


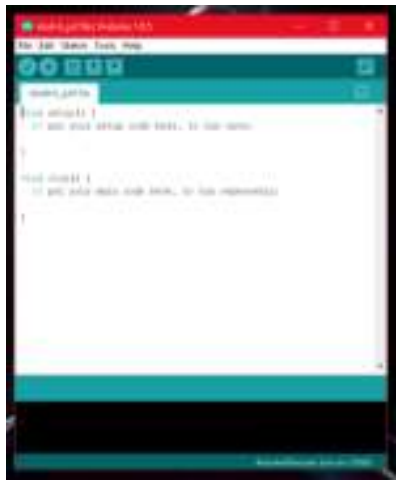

gambar 7 Sketch baru Arduino IDE

5. Buka Sketch Arduino IDE dengan kode dibawah ini.

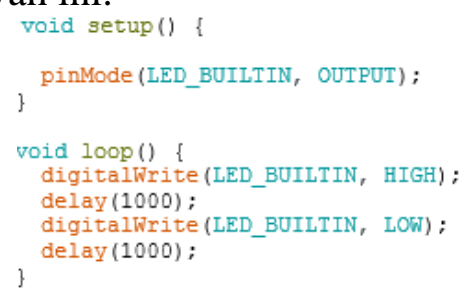

6. Setting board, serial port dan programmer sesuai dengan yang diinginkan

7. Kemudian upload sketch dan tunggu hingga selesai

8. Setelah upload selesai, kemudian membuat rangkaiannya.

\section{B. Hasil Pengujian}

Dari pengujian yang dilakukan berdasarkan prosedur pengujian RFID, maka akan diperoleh sampel data hasil pembacaan RFID dari beberapa sumber tag ID yang ditunjukan pada Tabel 4.3. dan dapat dipastikan pula RFID dapat berfungsi dengan baik untuk pembacaan tag ID dan dapat digunakan pada penelitian ini.

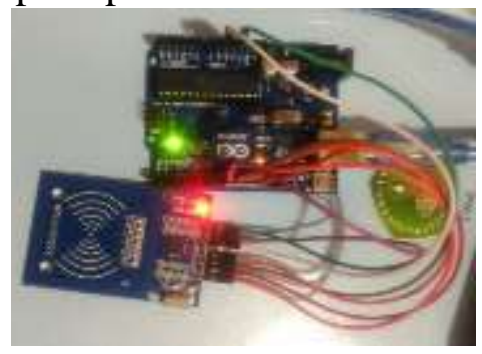

gambar 8 Hasil Rangkaian RFID dan Arduino
Table 1 Hasil sampel ID yang terbaca oleh RFID

\begin{tabular}{|c|c|l|l|l|}
\hline \multirow{2}{*}{ No } & \multirow{2}{*}{ SUMBER } & \multicolumn{3}{|c|}{ PEMBACAAN RFID } \\
\cline { 3 - 5 } & & \multicolumn{1}{|c|}{ Hasil 1 } & \multicolumn{1}{|c|}{ Hasil 2 } & \multicolumn{1}{|c|}{ Hasil 3 } \\
\hline 1. & Tag ID (1) & 13210217171252 & $\begin{array}{l}13210217171 \\
252\end{array}$ & $\begin{array}{l}13210217 \\
171252\end{array}$ \\
\hline 2. & Tag ID (2) & 9623416216313 & $\begin{array}{l}9623416216 \\
313\end{array}$ & $\begin{array}{l}9623416216 \\
\text { nyyyy}\end{array}$ \\
\hline
\end{tabular}

Kesimpulan dari tabel diatas yaitu dengan melakukan scan RFID sebanyak 3 kali untuk memastikan bahwa hasil ID yang di tag berbeda untuk setiap kartu sehingga kartu tidak akan tertukar satu dengan yang lainnya.

Tampilan hasil rangkaian sistem yang telah dirapikan dalam sebuah kotak sebagai gambaran untuk cara yang lebih mudah dalam pengaplikasian ke dalam pintu.

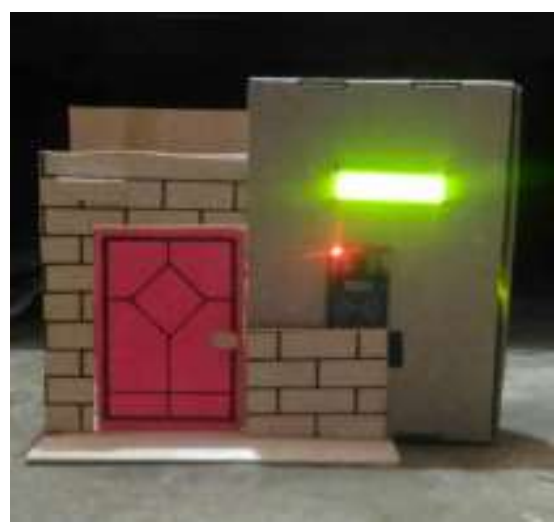

gambar 9 Pengaplikasian sistem

Hasil dari skenario 1 yaitu kondisi penambahan tag dengan ditandai buzzer berbunyi 1 kali dan kemudian melakukan pendaftaran untuk hak akses pada setiap pintu seperti yang ditunjukan pada tabel dibawah ini:

Table 2 Hasil Skenario

\begin{tabular}{|l|l|c|}
\hline No & \multicolumn{1}{|c|}{ Pintu } & \multicolumn{1}{|c|}{ ID } \\
\hline 1. & Pintu & 13210217171252 \\
\hline
\end{tabular}


Kesimpulan dari tabel diatas adalah dengan menggunakan ID : 13210217171252 maka user dapat membuka kunci pintu

Hasil dari skenario 2 yaitu kondisi sistem dalam keadaan siap untuk melakukan scan tag RFID.

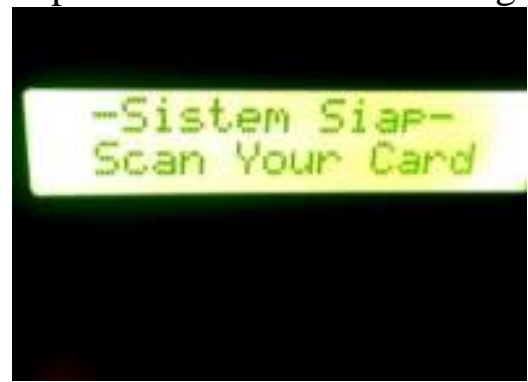

gambar 10 Tampilan sistem siap

User dapat mencoba melakukan scan dengan ID yang telah terdaftar maupun belum terdaftar, dari masing-masing percobaan akan menampilkan sebuah laporan pada LCD 16x2 apakah ID benar atau ID salah.

Hasil dari skenario 3 yaitu kondisi pintu terkunci, kemudian lakukan scan ID pada pintu dengan menggunakan ID yang telah terdaftar, yaitu : Pintu dengan ID : 13210217171252 Hasil skenario 3 dapat dilihat pada tabel dibawah ini:

Table 3 Hasil skenario 3

\begin{tabular}{|l|l|l|l|l|l|}
\hline \multirow{2}{*}{ No } & \multirow{2}{*}{ Pintu } & \multicolumn{1}{|c|}{ ID } & \multicolumn{3}{|c|}{ Door Lock } \\
\cline { 4 - 6 } & & & Uji 1 & Uji 2 & Uji 3 \\
\hline 1. & \multirow{2}{*}{ Pintu } & $\begin{array}{l}13210217 \\
171252\end{array}$ & 1 & 1 & 1 \\
\hline
\end{tabular}

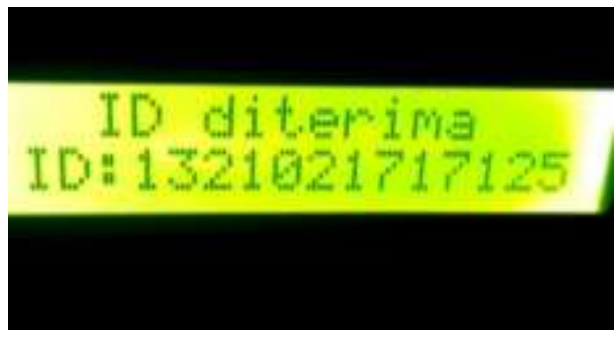

gambar 11 Tampilan ID diterima berbumyi 1 kali dan LCD menampilkan bahwa ID telah diterima.

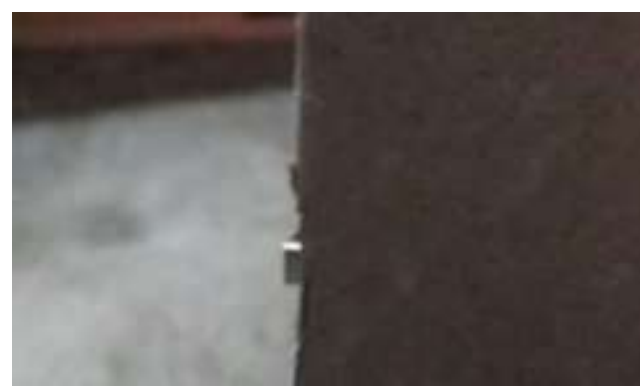

gambar 12 Tuas Door Lock memendek

Tuas Door Lock memendek karena teraliri listrik sehingga kunci pintu terbuka dan memberikan hak akses untuk masuk.

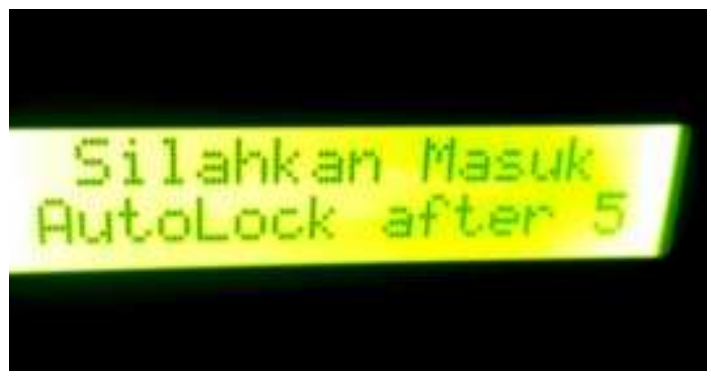

gambar 13 Tampilan AutoLock

Setelah melakukan Tag dengan ID yang benar dan akses diterima, maka sistem memberikan akses masuk selama 5 detik, dan akan secara otomatis terkunci kembali, dengan ditandai buzzer berbunyi 1 kali.

Kesimpulan dari tabel diatas adalah dengan menggunakan ID yang telah terdaftar dan sesuai untuk masing-masing pintu maka akan memberikan akses bagi user. Angka 1 pada uji coba diatas menandakan bahwa door lock telah teraliri arus sehingga tuas door lock memendek dan kunci pintu terbuka selama 5 detik dan setelah itu pintu akan terkunci secara otomatis.

Hasil dari skenario 4 yaitu kondisi kedua pintu terkunci, kemudian lakukan scan ID pada pintu dengan menggunakan ID yang belum terdaftar.

Melakukan tag dengan ID yang telah terdaftar akan memberikan hak akses yang ditandai buzzer 


\section{KESIMPULAN}

Table 4 Hasil Skenario 4

\begin{tabular}{|l|l|l|l|l|l|}
\hline \multirow{2}{*}{ No } & \multirow{2}{*}{ Pintu } & \multicolumn{2}{|c|}{ ID } & \multicolumn{3}{|c|}{ Door Lock } \\
\cline { 3 - 6 } & & \multicolumn{1}{|c|}{} & Uji 1 & Uji 2 & Uji 3 \\
\hline 1. & \multirow{2}{*}{ Pintu } & $\begin{array}{l}9623416216 \\
313\end{array}$ & 0 & 0 & 0 \\
\hline
\end{tabular}

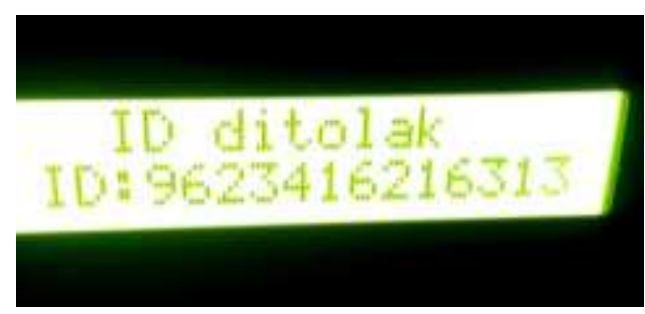

gambar 14 Tampilan ID ditolak

Melakukan tag dengan ID yang belum terdaftar tidak akan memberikan hak akses yang ditandai buzzer berbumyi 2 kali dan LCD menampilkan bahwa ID ditolak.

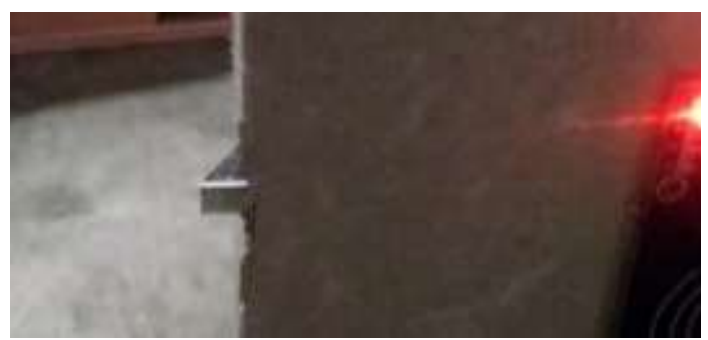

gambar 15 Tuas Door Lock tetap memanjang

Tuas Door Lock tetap memanjang karena tidak teraliri listrik sehingga kunci pintu tetap terkunci dan tidak memberikan hak akses untuk masuk. Kesimpulan dari tabel diatas adalah dengan menggunakan ID yang belum terdaftar maka tidak akan memberikan akses bagi user. Angka 0 pada uji coba diatas menandakan bahwa door lock tidak teraliri arus sehingga tuas door lock tetap memanjang dan kunci pintu terkunci

\section{A. Kesimpulan}

Berdasarkan pembahasan mengenai sistem keamanan kunci pintu pada SMKS Kesehatan Utama Insani menggunakan teknologi RFID yang telah dilakukan, maka dapat diambil kesimpulan sebagai berikut:

1. Sistem keamanan kunci pintu SMKS Kesehatan Utama Insani saat ini tidak otomatis serta belum ada pembatasan hak akses. Sehingga tidak ada aturan khusus untuk pemakaian ruangan yang berjalan saat ini.

2. Kendala yang terjadi pada sistem keamanan kunci pintu ruangan di SMKS Kesehatan Utama Insani yaitu banyaknya penggunaan ruangan tidak pada waktunya. Selain itu kurangnya kenyamanan serta ketertiban di lingkungan sekolah akibat kurangnya keamanan.

3. Sistem keamanan kunci pintu baru disusun berdasarkan kebutuhan akan fasilitas keamanan ruangan. Sistem tersebut berupa sistem keamanan kunci pintu yang terintegrasi dengan alat RFID. Sistem ini dapat mengatasi kelemahan sistem lama dari segi keamanan, kenyamanan dan proses.

\section{B. Saran}

Saran-saran yang diberikan adalah :

1. Dapat dilakukan perbandingan dengan metode keamanan kunci pintu yang lain untuk mendapatkan gambaran sistem mana yang sesuai dengan kondisi di SMKS Kesehatan Utama Insani.

2. Dapat dilakukan penelitian untuk mengkombinasikan sistem keamanan kunci pintu RFID dengan sistem pemarkiran.

3. Dapat dilakukan penelitian untuk mengkombinasikan sistem keamanan kunci pintu RFID dengan sistem pengontrol lampu otomatis, sehingga ketika pintu dibuka lampu akan otomatis menyala dan ketika pintu dikunci lampu akan otomatis padam, tentu sistem ini akan menghemat penggunaan listrik 


\section{REFERENS}

[1] A. Kadir, "Pengertian Sistem Informasi Menurut Abdul Kadir," in Pengenalan Sistem Informasi Edisi Revisi, 2014

[2] Yuhardiansyah, "ARDUINO MEGA 2560 REV 3," yuhardiansyahblog, 2016. .

[3] M. F. Wicaksono and T. R. Talma, "Perabot Multi Fungsi Berbasis Mikrokontroler,” Komputika J. Sist. Komput., 2018.

[4] R. H. Zain, "Sistem Keamanan Ruangan Menggunakan Sensor Passive Infra Red (PIR) Dilengkapi Kontrol Penerangan Pada Ruangan Berbasis Mikrokontroler Atmega8535 Dan Real Time Clock Ds1307," J. Teknol. Inf. dan Pendid, 2013. 